\title{
Perancangan Pengendalian Level Boiler dan Flow Bahan Bakar pada PLTU Bahan Bakar Sampah menggunakan Jaringan Syaraf Tiruan Backpropagation
}

\author{
Lilik Anifah* \\ Jurusan Fisika, FMIPA, Universitas Negeri Surabaya \\ Kampus UNESA, Ketintang, Surabaya 60321
}

\begin{abstract}
Intisari
Sampah adalah permasalahan klasik yang ada di masyarakat, untuk itu diperlukan penanganan serius dan terkendali oleh semua pihak. Penggunaan sampah sebagai bahan bakar PLTU sebenarnya sudah cukup lama dilakukan di negara-negara maju, terutama untuk keperluan rumah tangga maupun untuk industri kecil dan menengah. Berdasarkan analisis nilai kalor sampah di Surabaya yang diambil langsung dari rumah tangga adalah 3805,02 kal/gr, sedangkan yang diambil di TPA berkisar antara 745,41 kal/gr sampai dengan 2002,25 $\mathrm{kal} / \mathrm{gr}$. Sampah masuk ke dalam ruang pembakaran dengan menggunakan konveyor. Panas yang dihasilkan oleh pembakaran tersebut akan memanaskan air boiler. Steam yang dihasilkan oleh boiler akan memutar turbin. Telah dirancang sistem pengendalian level boiler dan flow bahan bakar pada PLTU bahan bakar sampah dengan menggunakan JST backpropagation, dengan hasil pada tracking setpoint untuk masukkan level 0 dan berbagai nilai bahan bakar, diperoleh error antara $9,61 \times 10^{-4} \%$ sampai dengan $9,95 \times 10^{-4} \%$.

KATA KUNCI: JST, Backpropagation, PLTU, sampah, boiler, level
\end{abstract}

\section{PENDAHULUAN}

Kota besar di Indonesia tidak pernah lepas dari permasalahan sampah. Misalnya di Surabaya tahun 1999 tiap bulan menghasilkan sampah $261,03 \mathrm{~m}^{3}$, sedangkan yang bisa diangkut dan ditangani oleh Pemerintah Daerah dengan armada sampahnya hanya $250,50 \mathrm{~m}^{3}[1]$.

Umumnya penanganan sampah yang dilakukan oleh masyarakat hanya sebatas penimbunan dan pembakaran. Proses pembakaran sampah yang dilakukan di tempat terbuka menyebabkan polusi udara dan menghasilkan residu yang mengganggu lingkungan. Padahal apabila pembakaran dilakukan di tempat tertutup dan terkendali, panas dan residu yang dihasilkan dapat dimanfaatkan pada industri rumah tangga sampai industri berskala besar.

PLTU bahan bakar sampah mempunyai keuntungan yaitu dapat mengurangi berat sampah sampai $80 \%$ dan mengurangi volumenya hingga 99\%. Kelebihan lainnya yaitu residu dari pembakaran ini masih dapat dimanfaatkan untuk keperluan lainnya. Seratus ton sampah dapat menghasilkan 5 - 6 Mwatt. PLTU bahan bakar sampah masih kompetitif bila dibandingkan pembangkit listrik lainnya. Unit pembangkit uap yang biasa disebut boiler plant merupakan peralatan utama yang dipergunakan dalam proses pengubahan energi panas pembakaran menjadi kinetis uap yang merupakan tekanan dan temperatur.

Kapasitas bahan bakar yang dibakar pada burner harus sebanding dengan produksi uap boiler. Flow bahan bakar yang

\footnotetext{
*E-MAIL: lilikanifah@yahoo.com
}

masuk ke burner harus diatu supaya pemanasan ruang bakar dapat merata dan efisien. Penyalaan boiler yang tidak bertimbang dengan beban akan mengakibatkan tekanan uap tidak stabil.

\section{TEORI PENUNJANG}

\section{A. Jaring Syaraf Tiruan (JST)}

Pembelajaran pada JST meliputi tiga tahap: pengenalan pola, backpropagation error, dan pengujian bobot. Setelah pembelajaran, aplikasi selanjutnya hanya melibatkan fase maju. Pada multilayer JST dengan satu unit hidden layer (unit Z), unit output (unit Y) dan unit hidden layer mempunyai bias. Bias pada unit output $\mathrm{Y}_{k}$ dinyatakan dengan $\mathrm{w}_{\text {ok }}$, dan bias dari $\mathrm{Z}_{j}$ dinyatakan dengan $\mathrm{v}_{o j}$. Bias ini berlaku seperti bobot pada sambungan tiap unit dengan keluarannya selalu bernilai 1. Selama fasa pembelajaran backpropagation sinyal dikirim dengan arah mundur.

\section{B. Algoritma JST}

Selama feedfoward tiap unit input $\left(\mathrm{x}_{i}\right)$ menerima sinyal input dan meneruskan sinyal ini ke unit hidden $\left(Z_{1}, \cdots, Z_{p}\right)$. Tiap unit hidden mengkomputasi fungsi aktivasi $\left(\mathrm{z}_{j}\right)$ pada tiap unit output. Tiap unit output $\left(\mathrm{Y}_{k}\right)$ mengkomputasi fungsi aktivasi $\left(\mathrm{y}_{k}\right)$ untuk membentuk respon tiap jaring untuk membentuk pola.

Selama pembelajaran tiap unit output dibandingkan dengan fungsi aktivasi $\mathrm{y}_{k}$ dengan nilai target $\mathrm{t}_{k}$ untuk menentukan er- 
ror dengan pola tersebut di tiap pola. Dengan error ini, faktor $\delta_{k}(\mathrm{k}=1, \cdots, \mathrm{m})$ didapatkan. $\delta_{k}$ digunakan unyuk mendistribusi error pada output unit $\mathrm{y}_{k}$ kembali ke unit pada layer sebelumnya digunakan juga untuk meng-upgrate bobot diantara output dan hidden layer. Demikian juga $\delta_{k}$ digunakan untuk menupdate bobot antara hidden layer dengan layer input.

Setelah semua diketahui, bobot semua layer diketahui secara simultan. Pengaturan pada bobot didasarkan pada $\delta_{k}$ dan fungsi aktivasi dari hidden unit. Pengaturan bobot $\mathrm{v}_{i j}$ (dari input unit ke hidden layer) didasarkkan dari $\delta_{k}$ dan fungsi aktivasi $\mathrm{x}_{i}$ dari unit input.

\section{Boiler}

Boiler adalah suatu jenis pesawat konversi untuk memproduksi uap pada jumlah tertentu setiap jamnya dengan tekanan dan temperatur yang telah ditetapkan. Boiler merupakan suatu bejana dari logam yang tertutup dimana air pada tekanan dan temperatur tertentu ditransformasikan menjadi uap dipindahkan guna memenuhi kebutuhan energi pesawat lain akan energi potensial uap, maupun energi termis/panas yang dibuuhkannuk pengolahan bahan produk secara langsung.

Penguapan bisa saja terjadi di sembanrang tempat dan waktu pada tekanan normat, bila diatas permukaan zat cait tekanan turun (atau diturunkan) di bawah tekanan mutlak. Uap yang dihasilkan dengan cara demikian tidak mempunyai energi potensial, sehingga tidak dapat dipergunakan sebagai energi. Oleh karena itu pemanasan air dalam boiler dilakukan dengan tekanan dan temperatur tertentu.

\section{Dinamika Proses Pembakaran pada Boiler}

Ada lima faktor penting yang dapat dikontrol yang menyangkut tentang pengontrollan pada boiler, antara lain tekanan steam, jumlah bahan bakar, jumlah udara pembakaran, perpindahan gas buang, suplay feed water.

Setiap sistem pengontrollan boiler harus diperkenalkan, membandingkan, dan mengkoordinasikan keempat faktor terakhir. Tekanan steam harus dipertahankan tetap setiap saat dan biasanya tekanan steam sebagai master kontrol impulse.

Drop tekanan steam menyebabkan bertambahya laju pembakaran begitu pula sebaliknya naiknya tekanan steam menyebabkan berkurangnya laju pembakaran. Umumnya pengontrollan boiler ditekankan pada pengontrolan boiler dan pengontrollan pembakaran.

Sistem monitor aliran bahan bakar, aliran udara, tekanan steam header, pengontrollan aliran bahan bakar dan aliran udara pembakaran ke furnace bertujuan untuk mempertahankan:

1. tekanan steam header pada nilai set yang dikehendaki.

2. perbandingan udara-udara bakar yang sesuai.

\section{E. Nilai Panas Pembakaran}

Nilai panas (kalor) yang didefinisikan sebagai energi panas yang dilepaskan saat terjadi oksidasi unsur-unsur kimia yang terdapat dalam bahan bakar. Hight Heating Value (HHV) adalah energi kimia tertinggi yang dilepaskan oleh bahan bakar selama terjadinya proses pembakaran.

$$
H H V=\Delta H C O+\Delta H_{2} \mathrm{O}+\Delta H_{S} \mathrm{O}_{2}+\Delta \mathrm{HCO}_{2}
$$

Berdasarkan analisis termodinamika kimiawi dengan temperatur reaksi $\mathrm{T}_{2}=453^{\circ} \mathrm{K}$ dan temperatur referensi $\mathrm{T}_{1}=298,15^{\circ} \mathrm{K}$, maka didapat:

$$
\begin{aligned}
H H V & =\left(24,284 C+79,883 H_{2}+13.874,815 S\right) \\
& \times 10^{6} \text { Btu } / l b
\end{aligned}
$$

dengan, $\mathrm{HHV}=$ nilai kalor tertinggi yang dapat dilepaskan dari pembakaran, $\mathrm{C}=$ jumlah karbon yang dikandung dalam 1 $\mathrm{kg}$ bahan bakar, $\mathrm{H}_{2}=$ jumlah hidrogen yang dikandung dalam $1 \mathrm{~kg}$ bahan bakar, $\mathrm{S}=$ jumlah sulfur yang dikandung dalam 1 $\mathrm{kg}$ bahan bakar

\section{F. Konsumsi Bahan Bakar}

Konsumsi bahan bakar boiler berhubungan dengan beban boiler dan efisiensinya pada beban tersebut. Konversi energi didalam boiler berlangsung dari panas pembakaran bahan bakar menjadipanas, (a). untuk produksi uap: $m s t\left(\mathrm{~h}_{2}-\mathrm{h}_{1}\right)$, (b). untuk pemanasan ulang uap: $\mathrm{mrh}\left(\mathrm{h}_{4}-\mathrm{h}_{3}\right)$, (c). terbuang dari blowdown: $\operatorname{mbld}\left(\mathrm{h}_{5}-\mathrm{h}_{1}\right)$, (d). terbuang sebagai rugi-rugi lain selain butir $\mathrm{c}$ di atas yang dimasukkan ke dalam efisiensi boiler.

Neraca energi boiler dituliskan dengan persamaan:

$$
M_{\text {fuel }}=\frac{m s t\left(h_{2}-h_{1}\right)+m r h\left(h_{4}-h_{3}\right)}{\eta_{b} . H H V}
$$

dengan, $\mathrm{HHV}=$ panas pembakaran tinggi, energi $/$ massa, $\mathrm{m}_{i}=$ laju aliran uap, massa/waktu, $\mathrm{m}_{\text {fuel }}=$ konsumsi bahan bakar, $\Delta_{b}=$ efisiensi termal boiler. Neraca entalpi boiler digambarkan seperti pada Gambar 1 .

Konsumsi bahan bakar seringkali juga dinyatakan dengan heat rate, yaitu dinyatakan dalam energi yang dikandung dalam bahan bakar untuk setiap satuan waktu. Konversi HHV menjadi LHV dapat dilakukan dengan mengetahui jumlah air yang terbentuk dalam pembakaran, sebagai hasil hidrogen dengan oksigen dan air kandungan bahan bakar.

$$
L H V=H H V-1040(9 H+W) B t u / l b
$$

dengan, $\mathrm{W}=$ massa air dalam bahan bakar (dasar kering), $\mathrm{H}$ $=$ fraksi elemen hidrogen (dasar kering), $1040=$ panas penguapan air, Btu/lb. Harga panas pembakaran bergantung pada jenis bahan bakar. 


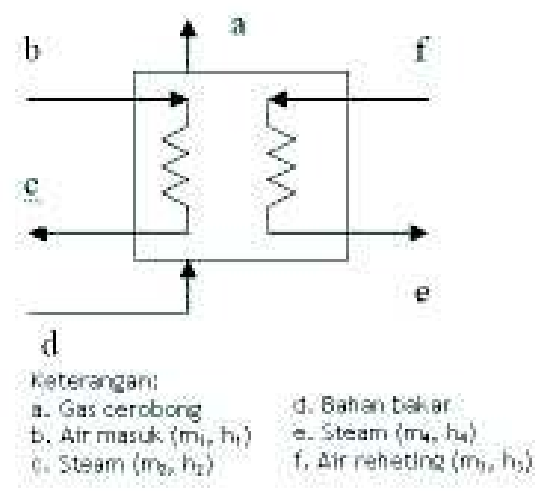

Gambar 1: Neraca entalpi Boiler

\section{G. Efisiensi Boiler}

Perhitungan efisiensi boiler terdapat dua macam:

1. Metode Perhitungan Efisiensi Netto

Metode ini dengan cara menghitung semua energi yang digunakan pada boiler, perumusan ini banyak digunakan di Eropa, dinyatakan dengan

$$
\eta_{b}=\frac{\text { panas yang digunakan }}{H H V} \times 100 \%
$$

\section{Metode Perhitungan Efisiensi Bruto}

Dengan cara menghitung semua energi yang hilang, definisi ini banyak digunakan di Amerika Serikat. Efisiensi boiler dinyatakan dengan

$$
\eta_{b}=\frac{H H V-\text { rugi panas }}{N H V} \times 100 \%
$$

dengan rugi panas meliputi DGL(Dry Gas Losses), ML (Moisture Losses), MCAL(Moisture Incombustion Air Losses), UCL (Uncombustion Carbon Losses) dan RUL (Ratiation and Unaccounted for Losses).

\section{DINAMIKA SISTEM DAN PERANCANGAN KONTROLLER}

\section{A. Identifikasi Plant}

Boiler yang digunakan pada penelitian ini adalah Boiler 701 Eckard PT. Leces Probolinggo. Boiler ini dapat menghasilkan uap maksimal 10 ton/jam dengan temperatur steam $440^{\circ} \mathrm{C}$ dan tekanan 44 Bar.

Level pada boiler akan selalu dijaga pada level 0 artinya posisi air dan steam adalah $50 \%$ dari steamdrum. Level pada boiler dipengaruhi oleh setpoint temperatur, tekanan dan jumlah steam yang dihasilkan. Level juga dipengaruhi oleh kondisi air pengisi dan jumlah suplay bahan bakar yang masuk. Karena itu keenam variabel di atas adalah variabel yang saling mempengaruhi.

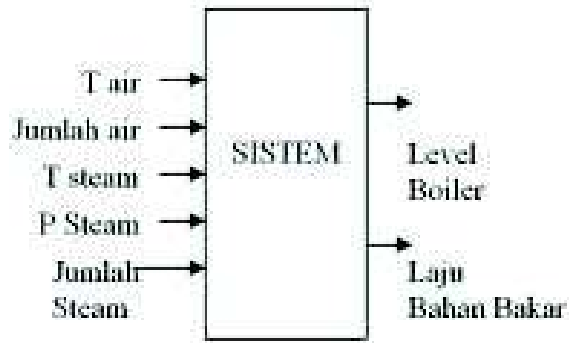

Gambar 2: Diagram blok sistem

Perancangan berbasis JST ini, penulis mengadakan dua tahap perancangan yaitu perancangan JST plant dan JST kontroller. Setiap tahap perancangan ini dilakukan simulasi untuk melihat respon dari JST plant dan JST kontroller yang dirancang.

Perancangan model plant dimaksudkan untuk mengidentifikasi plat dengan tujuan mendapatkan model plant berupa node-node dengan nilai bobot dan bias yang sesuai dengan real plant. Setelah mendapatkan model plant, maka dilakukan perancangan JST kontroller offline dan online. JST offline dimaksudkan untuk mendapatkan bobot dan bias awal pada JST online. Perancangan JST online dilakukan untuk melihat kemampuan dalam mengatasi perubahan setpoint dan gangguan dengan menggabungkan JST plant dan JST kontroller yang telah didapatkan sebelumnya.

\section{B. Perancangan JST Plant}

Pertama kali yang dilakukan adalah dengan mengumpulkan data-data input dan output dari lant. Kemudian datadata tersebut dilakukan perancangan JST plant dengan mengadakan pelatihan untuk mendapatkan nilai bobot dan bias tertentu dan bila nilai bobot dan bias telah didapat maka kita dapat membandingkan nilai output dari JST plant dari nilai output dari plant yang sesungguhnya, bila batas error telah terlampaui maka bobot dan bias tersebut telah dianggap sesuai.

Setelah dilakukan pelatihan berkali-kali akhirnya didapatkan ukuran JST yang paling sesuai untuk mendekali plant yang sebenarnya, (a). 1 input layer terdiri dari 5 node,(b). 2 hidden layer terdiri dari 10 node hidden layer dan 7 node hidden layer kedua,(c). 1 output layer yang terdiri dari 2 node.

Didapatkan struktur JST plant, maka dilakukan proses pengidentifikasian plant yang bertujuan mencari nilai bobot dan bias yang sesuai dengan plant yang sebenarnya. Nilai bobot dan bias ini dipengaruhi oleh nilai momentum dan learning rate. Nilai momentum dan learning rate diubahubah hingga didapatkan nilai bobot yang paling sesuai dengan plant. 


\section{Perancangan JST Kontroller}

Penentuan JST kontroller dilakukan dengan mencoba sampai didapatkan struktur yang paling sesuai. Akhirnya didapatkan struktur yang terbaik, yaitu: (a). 1 input yang terdiri 2 node, (b). 2 hidden layer yang terdiri dari 10 node hidden layer pertama dan 20 node hidden layer yang kedua,(c). 1 output layer yang terdiri dari 5 node.

Data input pada pelatihan JST plant akan menjadi input dari pelatikhan JST kontroller. Hasil pelatihan ini adalah nilainilai bobot dan bias yang akan digunakan sebagai bobot dan bias awal pelatihan online.

\section{Perancangan JST Kontroller online}

Tahap terakhir dari perancangan ini adalah pelatihan online JST kontroller dengan menggunakan nilai bobot dan bias awal yang berasal dari pelatihan offline. Struktur JST pada pelatihan online adalah gabungan struktur JST plant dan kontroller.

Level boiler dan laju bahan bakar real plant sementara outputnya adalah level boiler dan laju bahan bakar dari JST plant. Hasil dari pelatihan online ini adalah nilai bobot dan bias akhir yang akan digunakan pada tracking setpoint atau perubahan setpoint, dari sinilah kita akan mengetahui performansi dari sistem pengendalian lavel dan laju bahan bakar.

\section{ANALISIS DAN SIMULASI HASIL PERANCANGAN}

\section{A. Analisis Model Sistem}

Merancang model sistem dengan menggunakan JST terdapat parameter-parameter yang diperlukan untuk proses pelatihan pasangan data input-output dari plant, parameter yang dibutuhkan adalah:

- error yang diinginkan

- learning rate

- momentum

- jumlah epoch atau iterasi maksimum

Perancangan model plant (JST-Plant) digunakan parameter sebagai berikut:

- error minimal yang diinginkan adalah $10 \times 10^{-6}$ dari keluaran plant

- nilai momentum yang digunakan adalah 0,1 sampai 0,9

- jumlah epoch maksimum yang digunakan selama pelatihan adalah 10.000

Parameter tersebut digunakan dalam pelatihan untuk memperoleh model sistem (JST plant). Gambar error terkecil digambarkan pada Gambar 3. Pelatihan dengan error terkecil

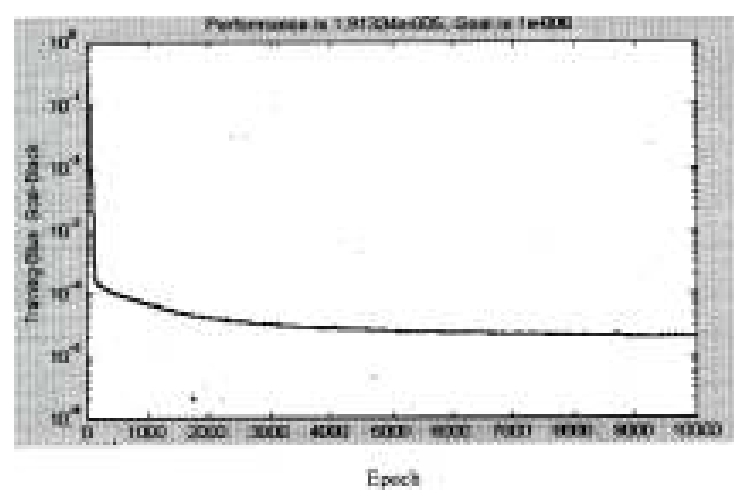

Gambar 3: Pelatihan plant JST

dilakukan dengan menggunakan learning rate 0,1 dan momentum 0,9 , error yang dicapai untuk pelatihan sebanyak 10.000 epoch adalah $1,91334 \times 10^{-5}$.

Setelah pelatihan JST plant dengan variasi learning rate dan momentum terdapat 81 variasi error yang menggambarkan performansi dari model plant JST, tujuan pelatihan ini adalah untuk menentukan model JST plant. Model JST plant yang digunakan adalah dengan learning rate 0,1 dan momentum 0,9 dan error yang dicapai untuk pelatihan selama 10.000 epoch adalah $1,91334 \times 10^{-5}$. Dari model JST plant ini akan diperoleh bobot dan bias yang akan digunakan dalam pelatihan online kontroller JST.

\section{B. Analisis Performansi Kontroller JST secara offline}

Pelatihan JST kontroller secara offline adalah pelatihan kontroller JST dengan metode hubungan terputus, dimana kontroller JST tidak dihubungakan dengan plant. Pelatihan offline kontroller JST tidak dihubungkan dengan plant. Metode yang digunakan untuk pelatihan hampir sama dengan pelatihan JST plant yaitu dengan melatih struktur kontroller JST yang akan dirancang berdasarkan pasangan data input dan output. Input dari pelatihan kontroler JST ini adalah level boiler dan laju bahan bakardari boiler, sedangkan outputnya adalah sinyal kontrol atau variabel yang mempengaruhi level boiler dan laju bahan bakar dari boiler.

Dalam merancang kontroler JST secara offline digunakan parameter JST seperti yang digunakan pada pelatihan model JST seperti pada pelatihan model JST plant. Pelatihan JST kontroller ini dilakukan dengan menggunakan JST Backpropagation. Parameter learning rate yang digunakan antara 0,1 sampai dengan 0,9 dan momentum antara 0,1 sampai dengan 0,9 . Pemilihan nilai parameter learning rate dan momentum ini digunakan karena hasil pelatihan yang telah dilakukan nilai parameter tersebut menunjukkan performansi terbaik. Untuk parameter error yang dipakai pada pelatihan nilai error yang dikehendaki adalah $10^{-5}$, dan nilai epoch maksimal yang digunakan adalah 10.000 epoch. Gambar 4 merupakan hasil pelatihan kontroler dengan learning rate 0,5 dan momentum 0,9 , error yang dicapai sebesar $4,16113 \times 10^{-3}$. 


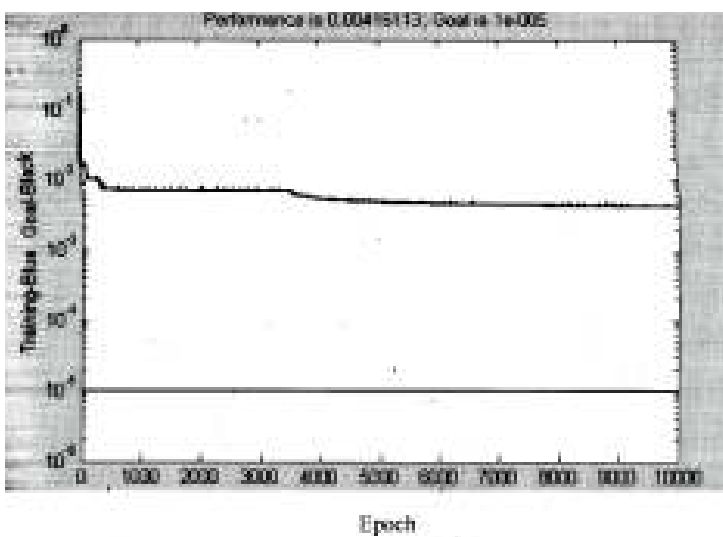

Gambar 4: Pelatihan JST kontroller offline

Hasil pelatihan kontroler JST secara offline yang dilakukan diperoleh 81 variasi pelatihan error berdasarkan parameter pelatihan learning rate dan momentum yang menggambarkan performansi dan kontroler JST. Tujuan dari pelatihan JST kontroler secara offline adalah untuk mendapatkan bobot dan bias kontroler JST yang dipilih berdasarkan nilai error pelatihan terbaik dan epoch pelatihan. Berdasarkan hasil pelatihan kontroler didapatkan JST offline yang dipilih adalah kontroler dengan learning rate 0,5 dan momentum 0,9 . Bobot dan bias dari pelatihan kontroler JST dengan learning rate 0,5 dan momentum 0,9 ini digunakan untuk pelatihan kontroler JST online.

\section{Analisis Performansi Kontroler JST online}

Pada pelatihan online ini dilakukan dengan menggabungkan hasil pelatihan sebelumnya yaitu pelatihan JST plant dan JST kontroller offline Gabungan dua pelatihan ini meliputi struktur dari JST-nya yaitu JST plant dan JST kontroler yang terdiri jumlah layer, nilai bobot dan bias. Untuk mendapatkan performansi yang baik, perlu diperhatihan hal-hal seperti bobot dan bias yang digunakan harus berasal dari proses pelatihan dengan nilai error yang terkecil dan kecepatan pelatihan yang paling sedikit.

Setelah nilai bobot dan bias tersebut ditentukan mana yang akan dipakai, maka proses pelatihan online bisa dilakukan. Proses pelatihan ini dilakukan untuk mengetahui sejauh mana performansi sistem gabungan dari JST plant dan JST kontroler yang terdiri dari jumlah layer, nilai bobot dan bias. Untuk mengetahui performansi tersebut, maka digunakan datadata yang diperoleh dari plat (data pertama) dan diujikan juga dengan data-data yang baru. Pada proses pelatihan online ini parameter pelatihan yang digunakan adalah nilai learning rate dan nilai momentum. nilai momentum diset pada 0,9 sedangkan nilai learning rate berkisar antara 0,1 dan 0,9 . Performansi dari pelatihan online ini dapat dilihat dari nilai error yang diperoleh terhadap keluaran plant. Berikut adalah gambar yang menunjukkan respon dari sistem tersebut. Berdasarkan pelatihan online untuk nilai learning rate

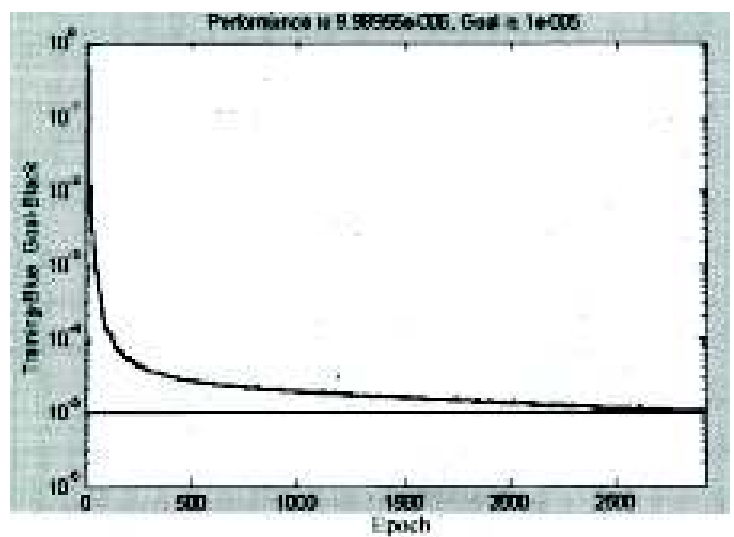

Gambar 5: Pelatihan JST kontroller online

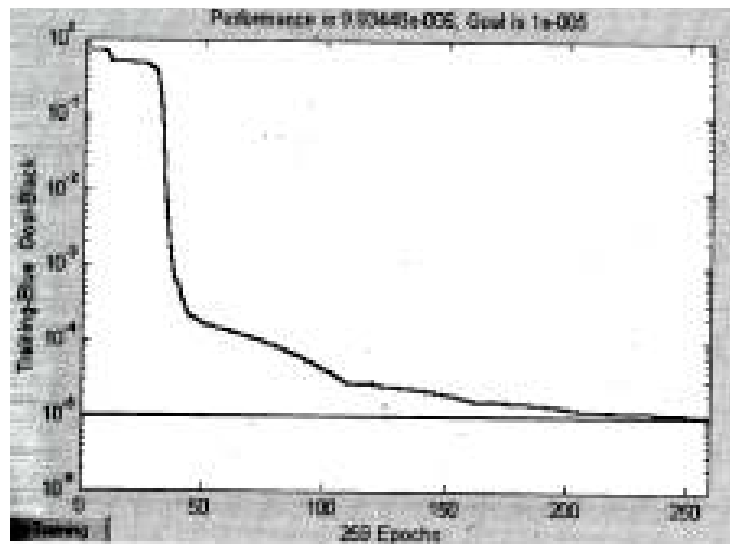

Gambar 6: error ltracking setpoint dengan setpoint level 0 dan setpoint laju bahan bakar 110.000

0,5 dan nilai momentum sebesar 0,7 diperoleh error sebesar $9,99956 \times 10^{-6}$ selama 2917 epoch .

Dari hasil pelatihan online yang dilakukan diperoleh 81 variasi pelatihan error berdasarkan parameter pelatihan learning rate dan momentum yang menggambarkan performansi dari kontroler JST online hasil gabungan antara kontroler JST dengan plant JST. Tujuan dari pelatihan online adalah untuk mendapatkan bobot dan bias kontroler JST online yang dipilih berdasarkan nilai error pelatihan terbaik dan lama epoch pelatihan. Dari hasil pelatihan kontroler secara online maka kontrol JST online yang dipilih adalah kontroler dengan learning rate 0,8 dan momentum 0,9 ini digunakan untuk uji tracking setpoint.

\section{Analisis Pengujian Tracking Setpoint}

Setelah melakukan pelatihan online dengan data plant maka untuk mengetahui performansi dari kontroler JST dan plant JST dilakukan pengujian tracking setpoint. Pada uji tracking setpoint ini akan diberikan setpoint baru yang berbeda dari data plant. Untuk uji ltracking setpoint ini selain error 


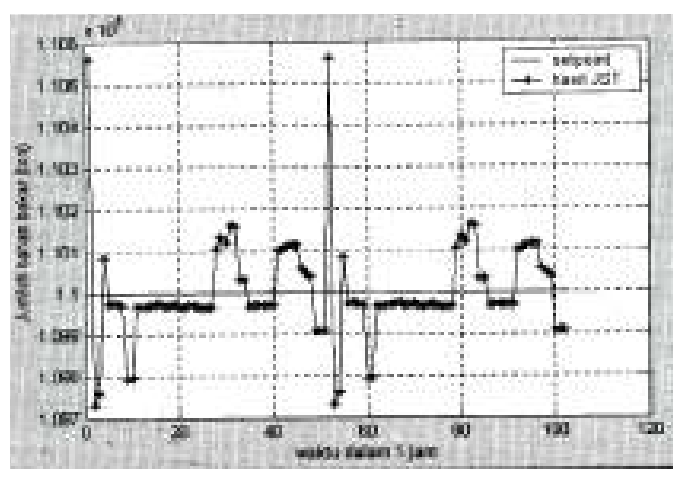

(a)

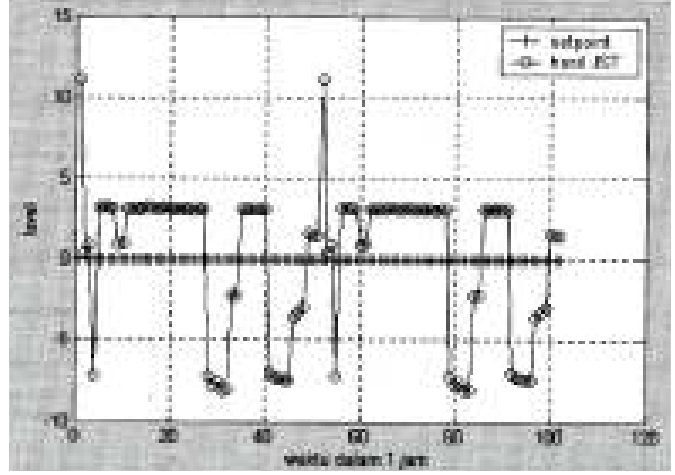

(b)

Gambar 7: Hasil (a). error dan (b). tracking setpoint laju bahan bakar $110.000 \mathrm{~kg} / \mathrm{jam}$ dan setpoint level 0

pelatihan juga diuji output plant dan output JST. Uji ltracking setpoint diberikan setpoint baru yang berbeda dari data plant. Untuk tracking setpoint ini selain error pelatihan juga diuji output plant dan output JST.

Gambar 6 menunjukkan bahwa user menetapkan setpoint level 0 dan laju bahan bakar $110.000 \mathrm{~kg} / \mathrm{jam}$ dengan menetapkan error $1 \times 10^{-5}$ maka proses akan selesai pada epoch ke 259. Keluaran JST kontroler terhadap setpoint digambarkan pada Gambar 7. Tampak jelas bahwa JST kontroler mengikuti setpoint dengan pendekatan sesuai dengan nilai error yang telah ditetapkan.

\section{SIMPULAN}

Berdasarkan analisis dan pengujian yang telah dilakukan maka dapat diambil kesimpulan, antara lain:

- Dengan JST dapat diperoleh model sistem plant dari boiler untuk mengendalikan level dan laju bahan bakar melalui identifikasi plant (JST plant). Model JST plant mempunyai konfigurasi 5 node layer input, 10 node hid- den layer pertama, 7 node hidden layer kedua dan 2 node output layer dengan parameter pelatihan learning rate sebesar 0,1 dan momentum sebesar 0,9 diperoleh error pelatihan sebesar $1,91334 \times 10^{-5}$.

- Struktur JST kontroler pada pelatihan offline memiliki konfigurasi 2 node input layer, 10 node hidden layer pertama, 20 node hidden layer kedua dan 5 node output laye dengan parameter pelatihan learning rate sebesar 0,5 dan momentum sebesar 0,9 diperoleh error pelatihan sebesar $4,161134 \times 10^{-3}$.

- Pelatihan online dengan menggunakan data asli plant, dengan parameter pelatihan learning rate sebesar 0,5 dan momentum sebesar 0,7 diperoleh error pelatihan

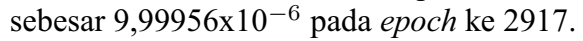

- Pengujian ltracking setpoint untuk masukan level 0 dan berbagai nilai laju bahan bakar, diperoleh prosentase error antara $9,61 \times 10^{-4 \%}$ dampai dengan $9,95 \times 10^{-4} \%$.
[1] Biro Badan Statistik, Surabaya dalam Angka 2000 (Badan Biro Statistik, Surabaya, 2000).

[2] Cairo Nascimento, Artificial Neural Network ini Control and Optimation (Faculty of Technology, Univ. of Manchester, 1994).

[3] Djokosetyardjo, Ketel Uap (PT Pradya Paramita, Jakarta, 1999).

[4] Fausett, L., Fundamental of Neural Network (Architectures, Algorithms and Aplication) (Prentice Hall International Inc., 1994).

[5] Frans Gunterus, Falsafah Dasar: Sistem Pengendalian Proses(Elex Media Komputindo, 1994).

[6] Demuth, Beale, Neural Network Toolbox for Matlab (Mathwork Inc, 2001).

[7] Letjes, Operating Instruction for SKG Water Tube Boiler (Kessel, Duisbeurg, 1982).

[8] Smith, JM., Introduction to Chemical Engineering Thermodynamics(McGraw Hill Companies, Singapura, 1996).

[9] Susanto, Herri, Sistem Utilitas II (ITB. Bandung, 2000).

[10] Winarto, Agus, Penerapan Fuzzy Prakompensator untuk Kon- troller PID pada Sistem Pengendalian Boiler, Tugas Akhir, ITS Surabaya, Surabaya, 2000.

[11] Freeman, Skapura, Neural Network (Algorithm, Aplication and Programming Technique) (Adison Wesley Publishing Company Inc., 1992)

[12] Moscinski, Ogonowski, Advanced Control with Matlab and Simulink (Prentice Hall International Inc., 1995).

[13] Norgard, Poulsen, Hansen, Neural Network for Modelling and Control of Dynamic System (Springer Verlag, London, 2000).

[14] Schalkoff, Pattern Recognition, Statiscal, Structural and Neural Approuches (John Willey and Son inc., 1994).

[15] ABB. Combustion, PLTU Paiton, 1990.

[16] Anifah, Puspasari, Rachmawardani, Pengolahan Sampah Rumah Tangga sebagai Alternatif Pembangkit Energi Listrik, ITS Surabaya. Surabaya, 2002 